\title{
Review of plant health clinics: a recent phenomenon for effective plant pests and diseases diagnosis
}

Rambauli, M. ${ }^{1}$, Antwi, A.M. ${ }^{2}$ and Mudau, F.N. ${ }^{3}$

Correspondence author: M Rambauli, E-mail: mrrambauli@gmail.com

\begin{abstract}
Plant health clinic is a mechanism in which farmers are able to access basic plant healthcare and services from relevant authority in relation to infested or suspected infested plants and plant products for diagnostic purposes. Plant health clinic is an integral part of the plant health system which provides early pest diagnostic and advisory services to farmers. In this paper, it can be further defined as a basic plant healthcare rendered to farmers to enhance and improve plant production thereby diagnosing plant pests and diseases with the aim of employing appropriate pest management strategy. In many countries, plant health clinics operators are extension experts, plant doctors, inspectors and scientists within government and NGOs. Extension support in particular is critical in the operation of plant health clinics. The purpose of this paper is to provide a global overview of plant clinic as a recent ways of plant diseases diagnosis. This paper concluded that plant health clinics are valuable tools which need to be adopted by various countries for smallholder farmers to understand more about plant pests and diseases as well as management strategy. To the contrary, many countries are dependent on national diagnostic services as opposed to basic plant healthcare which is more accessible to the smallholders. This review paper further revealed that plant health clinics' knowledge, awareness, accessibility and satisfaction of the smallholder farmers are very important. Plant clinics may not efficiently and effectively operate in the absence of the aforementioned aspects. Plant clinics were found to be the most efficient way to reach smallholder farmers for advice.
\end{abstract}

Keywords: Plant health clinics, smallholder farmers, extension support

\section{INTRODUCTION}

Globally, the agricultural sector plays an important role in poverty reduction, food security and promotion of nutritious food (Jone \& Ejeta, 2016). Although agricultural crop production is essential, there are challenges associated with plants due to pests and diseases infestation in the value chain of crop production. Plant health problems can be resolved through appropriate diagnosis and identification of plant pests affecting agricultural (Ausher et al., 1996). However,

\footnotetext{
${ }^{1} \mathrm{PhD}$ Student: Scientist Manager and the Executive Officer of the Agricultural Pests Act, 1983 (Act No.36 of 1983), Division Policies, Norms and Standards, Directorate: Plant Health, Department of Agriculture, Land Reform and Rural Development, Private Bag X14, Gezina, Pretoria, 0031, E-mail: MaandaR@ Dalrrd.gov.za; Tel: 012319 6164; https://orcid.org/0000-0002-2747-1481

2 Professor: Postgraduate Research Coordinator for Master and $\mathrm{PhD}$ in Agriculture, College of Agriculture \& Environmental Sciences (CAES), Agriculture \& Animal Health Department, University of South Africa, Florida Campus, Calabash Building, Room 332B; e-mail: antwima@unisa.ac.za; Tel: 011 6719391; https://orcid.org/000.0003-3896-4502

${ }^{3}$ Professor: Dean \& Head of School: School of Agricultural, Earth and Environmental Sciences, University of KwaZulu-Natal, P. Bag X01, Scottsville 3209, Pietermaritzburg, South Africa, MudauF@ukzn.ac.za; the Author is also a Professor Extraordinarius : in the Department of Agriculture and Animal Health. University of South Africa; Tel: 2733260 6076; https://orcid.org/0000-0003-3623-6421
} 
Oerke (2006) reported that $40 \%$ of crop yield losses are caused by plant pests and diseases of economic importance. The majority of smallholder farmers are faced with risks associated with pests and diseases in plant production. To address challenges faced by smallholder farmers, plant health clinics are important for plant pests and disease diagnosis. The plant health clinics can be defined as a system in which farmers obtain advisory services on the plant pest problem affecting agricultural crops and provide management control strategy for pest management (Alokit et al., 2015). There are many plant health clinics initiatives within the African region that provides plant pests and diseases advisory services to all categories of the farmers (Boa et al., 2016). Many plant clinics in developing countries which are run by international research institutions are more efficient and effective as compared to those not run by the research institutions.

This review seeks to investigate and assess the state of global plant clinics with the aim of obtaining the efficient and effective plant health clinic model for South Africa. The knowledge, awareness, availability and accessibility of basic plant healthcare to smallholder farmers for plant pests and diseases diagnosis to ensure early detection, pest management and pest reporting remain a challenge. Furthermore, there is limited literature and research on plant health clinics' establishment and its importance to smallholder farmers in the African developing country.

\section{BACKGROUND OF THE PLANT HEALTH CLINICS}

To date, there are about 34 countries operating plant health clinics globally and it is estimated that there are 4500 plant clinics across the globe Centre for Agriculture and Biosciences International (CABI), 2020; Tambo et al., 2020). These include plant clinics in Africa, South America and Asia respectively (Boa, 2009; CABI 2020). The first plant health clinics were established in 2003 in Bolivia (Bentley et al., 2009; Boa, 2009). In Africa alone, plant clinics were established with the help of CABI to assist smallholders and household to respond effectively and efficiently towards plant pests and diseases.

According to Boa et al. (2016), there are two types of plant health clinics in terms of service provisions, namely (1) Fixed structure with appropriate laboratory equipment for identification of pests and diseases (2) extension support through mobile plant clinic or community-based clinic. Mobile plant health clinic is the most valuable tool for smallholder farmers' accessibility. According to Adhikari et al. (2017), plant health clinic is a critical system approach to provide immediate service to smallholder farmers. Although plant clinics are critical, Majuga at el. (2018) indicated that not much is known on the operation of the clinics and their importance. Accordingly, plant health clinics can prompt official pest reporting obligations, policy formulation, official pest status of a country, as well as official early warning and/or pest management actions (FAO, 2011, RSA, 2017, DAFF, 2017).

In the year between 2000-2009, plant health clinics in Bolivia were found to assist large number of communities and farmers in terms of provision of advisory services on disease and pests 
which led to less usage of pesticides (Bentley, 2011). In Nepal, plant health clinics were established with the purpose to enable farmers to excess primary plant health services (Adhikari, 2009). Boa and Harling (2008) reported that the Nepal Government was found to have limited resources and fragmented organisational structure in relation to plant health clinics. The plant health clinics training in Nepal are run by the Global Plant Clinic (GPC) which is offered to agriculturists on how to become plant doctors. The GPC suggested that agricultural scientists can play a major role to assist farmers. According to Harling and Boa (2007), the Global Plant Clinic falls under the CABI and this involves various stakeholders such as researchers, agricultural extension and government in order to provide a technical advisory to the majority of poor farmers.

In Kenya, through plant health clinic, it was found that factors affecting crop production at smallholder farmers' level include biotic and abiotic factors (Kansiime et al., 2020). In this regard most farmers were advised to implement Integrated Pest Management (Ochilo et al., 2018). In Uganda, mobile plant health clinics were established in 2005 to assist smallholder farmers to resolve plant health problems (Danielsen, 2010). A study conducted by Brubaker $e t$ al. (2013) in Uganda found that the impact of the exiting plant health clinics do not influence farmers perception on farming practice due to various reasons which include required resources, lack of awareness and information management. In Rwanda plant health clinics were found to enhance food production and security (Tambo et al., 2020). This is because most smallholder farmers were found to visit plant clinics often. Plant clinics are more effective and efficient if the required resources are employed for excellent service delivery in terms of pest identification and management. also share the same sentiment (Alokit et al. 2014; Azimi et al. 2017).

Globally, the impact of plant health clinics is to diagnose pests and diseases timely and to ensure food production and security thereby employing integrated pest management strategy (Srivastava, 2013). The Republic of South Africa (2017) outline the importance and procedure for pest reporting procedures of regulated pests and/or new pest. Pest reporting promotes sharing of data and knowledge (Plantwise, 2014). Boa (2015) indicated in countries where plant clinics exist, awareness to inform farmers to bring diseases plant samples for appropriate advice and recommendations to manage and control the disease is critical. The Food and Agriculture Organisation (FAO) (2018) describe plant pest surveillance as an important element for pest reporting obligation within trading partners. In the United State of America (USA), surveillance to detect a new pest or pest of economic importance is conducted through the Cooperative Agricultural Pest Survey Program (CAPSP) which includes industry, farmers and universities. This program does not only consist of government authority (Jackson, 2011). Accordingly, it implies that surveillance should involve and be performed by many stakeholders. In South Africa, surveillance is coordinated by the National Plant Protection Organization of South Africa (NPPOZA) within the Department of Agriculture, Land Reform and Rural Development (DALRRD) in accordance with international prescripts and relevant action plans (Republic of South Africa, 2014, DAFF, 2017). 
Plant pest surveillance and plant clinics are critical for early pest detection, recognition of pest status in an area, host plant list and pest reporting (FAO, 2018; DAFF, 2017; Kalaris et al., 2014). Majuga et al. (2018) pointed out that smallholder farmers sometimes get demotivated to report any symptoms because the response from the plant clinic is sometime delayed. Wright et al. (2016) recommended that information and communication technology (ICT e.g. Smartphones) as an important tool for e smallholder farmers to report immediately of any occurrence and suspected occurrence of plant pests. The ICT was found to be a quick and critical tool for pest reporting as well as for the "plant doctors" to provide plant pest advisory in terms of pest management option to affected farmer/s. In this regard, farmers can use smartphones to take picture of suspected samples and/or infested plants and send to the relevant authority. The initiative to use ICT or smartphone by smallholder farmers requires government support to smallholder farmers as this approach can drastically cut travelling costs (Musungwini, 2018). However, Chi and Yamada (2002) suggested that many farmers experience challenges in adapting to new technologies, especially in the absence of appropriate training from extension officers.

Although plant clinics are significant, plant health matters are highly neglected in many countries although these have a direct impact to availability of food in a society. In many developing countries, crop production is found to be low due to plant health challenges, therefore it is crucial to address plant health problem promptly in reducing poverty whilst increasing food production and security (Flood, 2010). Plant health clinics contribute in providing advisory to smallholder farmers on plant health problem. This supports smallholder farmers and ultimately assists various Organs of State to make informed decision regarding the modalities around plant health clinic. Organs of state include research institutes, Provincial Department of Agriculture (PDAs) and components responsible for plant health matters (Danielsen et al., 2013). This can further assist smallholder farmers in obtaining advisory services regarding plant health problem and pest reporting mechanism to the relevant authorities for better pest management and control strategies (Republic of South Africa, 2017).

\subsection{Plant health clinic: Regional perspective}

Most of developing countries established plant health clinics after 2003 with the aim to provide timely advisory services which is cost effective and efficient to smallholder farmers (Danielsen \& Kelly, 2010). In the African region, the majority of smallholder farmers do experience challenges regarding pest identification and control approach towards pest infestation (Boa et al., 2016). Lack of early pest detection or pest diagnosis may have a negative impact towards a sustainable food production and security (Srivastava, 2013). The introduction of exotic plant pests and diseases has increased over the decade and most smallholder farmers will need accessible plant health clinics for pest and disease diagnosis as well as identification in order to propose best plant pest management strategy for their control (Vakilian, 2017). In other countries such as Uganda, plant health clinics are regarded as an extension approach to assist farmers to detect pests early (Karubanga et al., 2017). In Uganda and Kenya, smallholder farmers have access to several established plant health clinics (Danielsen \& Matsiko, 2016). 
Generally, it is perceived that in Africa extensionists do not provide smallholder farmers with necessary support they need (Boa et al., 2016). Furthermore, the smallholder farmers may not know the pests affecting their crops/ production. Plant pests and diseases of economic importance are considered a huge threat to food production and security (Srivastava, 2018). Srivastava (2013) expressed the importance for plant health management to ensure suitable food production and security. Worldwide, the reduction in crop yield may be prevented through various pest management strategies including plant health clinics which provide recommendations to farmers and application of registered pesticides (Srivastava, 2013; Srivastava , 2018).However, in some developing countries the availability and accessibility of plant health clinics is far beyond the reach of poor-resource farmers especially in rural communities. The accessibility of plant health clinics remains a critical challenge to smallholder farmers including accessing critical services such as diagnosis of new diseases (Karubanga et al., 2017).

\subsection{National perspective of plant clinic}

In South Africa, plant health clinic was established by the Agricultural Research Council (ARC) with the collaboration of the Centre for Agriculture and Bioscience (CABI), and the Provincial Department of Agriculture in Limpopo Province (PDA) (ARC, 2018). The plant health clinic in Limpopo, Vhembe District was established in 2014 in Limpopo Province. The type of plant clinic established was "Mobile Plant Clinic" and/or extension support reaching to the farmers during farmers' events such as farmers' day (Van der Linde \& Rong, 2019). According to the record of the Limpopo Department of Agriculture, the Vhembe District, extension officers were trained about the role of plant clinic to support smallholder farmers in various irrigation vegetable schemes. In South Africa, national pests reporting regarding the occurrence of new plant pest that are under official control is compulsory under the National Control Measures R.110 of 27 January 1984, as amended under Agricultural Pests Act, 1983 (Act No.36 of 1983) (Republic of South Africa, 2017). The plant clinics can prompt official pest reporting obligations in terms of national legislation and international prescripts which led to declaring pest status of a country and providing early warning/ pest management actions (FAO, 2011, Republic of South Africa, 2017, DAFF, 2017).

\subsection{Smallholder farmers' knowledge, awareness, accessibility and satisfaction of plant health clinics}

Plant health clinics provide primary plant health services through advisory and recommendations provided to the farmers (Negussie et al., 2011). According to Boa et al. (2016) there are two types of plan health clinics in terms of services provision, namely (1) "Institute-based plant clinics have laboratory facilities for identifying pests and pathogens" (2) "Clinics that offer management advice through extension intermediaries"/usually called mobile plant clinic. Most smallholder farmers are unlikely to know of such clinics because of lack awareness of such clinic (Musebe et al.,2018). Boa et al. (2016) further indicated that most smallholder farmers are not aware of service provisions of different type of clinics. Usually farmers do not necessarily implement the advices provided on plant pests and diseases problem 
from plant health clinics because such recommendations are costly (Bentley et al., 2018). Luqman et al. (2020) recommended that to promote accessibility in plant clinics, clinics should be in a central place where farmers could be able to reach and access the plant healthcare services.

According to Adhikari et al. (2016) farmers' demography which includes gender, age and the size of the land influence their participation in plant health clinics. Plant clinics are established to be inclusive in term of demography which includes both genders and age group. However, in many developing countries, women and youth are not well represented in this initiative (Karubanga et al., 2017; Bently et al., 2011). According to Musebe et al. (2018), in Kenya male farmers are more aware of plant clinic than female farmers. Worldwide, the majority of smallholder farmers find information on plant health clinics helpful (Cameron et al., 2016). Awareness is a viable tool to encourage participation of farmers to the plant health clinic activities regardless of their gender (Musebe et al., 2018). Plant health clinics are found to be the main source of information which may help farmers on their agricultural field of practice. The majority of farmers in rural areas find it difficult to control and manage plant pests and diseases affecting their crop production (Musebe et al., 2018). In most cases, appropriate advisory on plant pests and diseases do not reach the majority of farmers and farmers are not aware of the roles and services that plant clinics provide (Boa et al., 2016). Primary plant healthcare is demand driven by the farmers and it enhances extension support to the smallholder farmers (Adhikari et al., 2015).

According to Danielsen et al. (2013), most plant health doctors or extensionists require an extensive awareness and/or regular training on pests, symptoms identification, diagnosis as well as pest control and management. Rambauli et al. (2019) conducted a study to determine knowledge gaps between the extensionist or agricultural advisors from the PDAs of South Africa and the officials of the national Department of Agriculture, Land Reform and Rural Development. It was found that many PDAs officials or extensionists lack knowledge on plant health issues: plant pests and diseases of economic importance (Rambauli et al., 2019).

\subsection{Determinants of smallholder farmers' knowledge, awareness, accessibility and satisfaction in the plant health clinic}

There are many factors contributing either positively or negatively in terms of the knowledge, awareness, accessibility and satisfaction of smallholder farmers regarding the plant health clinic. These factors include age, genders, farmer's membership, contact with the extension officer and size of farms (Adhikari et al., 2016). According to Madula et al. (2016), other factors which may contribute to the farmers' participation in the plant health clinics include age, gender, marital status, literacy level, land ownership, radio ownership and phone ownership. In the study conducted by Adhikari et al. (2016) in Nepal, it was suggested that farmers who belong to association groups or cooperative are more likely to be knowledgeable and aware of their participation in plant clinics. 
Agricultural groups or associations are very useful for farmers' interaction and exchanging ideas on issues relating to plant clinics (Martey et al., 2014). According to the study conducted by Etwire et al. (2013), access to extension support, training and education were found to contribute highly positively to the level of knowledge and awareness of smallholder farmers. Therefore, based on various authors (Adhikari et al., 2016; Etwire et al., 2013; Martey et al., 2014; Madula et al., 2016), it can be deduced that the following are determinants of smallholder farmers' knowledge, awareness accessibility and satisfaction of plant health clinics: age, gender, farmer's membership, contact with the extension officer, size of farm, marital status, literacy level, training, land ownership, radio ownership and phone ownership.

The accessibility of plant health by smallholder farmers for plant pests and diseases diagnosis to ensure early detection, pest management and pest reporting remain a challenge in many developing countries. According to Benin et al. (2007) and Bukenya (2010) pests and diseases can cause a devastating damage to crops if left unmonitored and unattended and this may affect food production and security. In this case, plant health clinics approaches have been introduced and used in many countries to assist smallholder farmers to address plant health problems (Bandara \& Kulatunga, 2012; Danielesen et al., 2014).

The study conducted by Madula et al. (2016) in Malawi revealed that the majority of smallholder farmers find plant clinic more helpful in terms of plant pests and diseases identification. Although the minorities of farmers were found not to be satisfied with the services stating different reasons such as lack of agrochemicals and inappropriate opening time (Madula et al., 2016). In the study conducted by Bentley et al. (2018) in Costa Rica, Napal and Malawi most farmers were found to be reluctant to take advice from the plant clinic due to fear of adopting to new technologies. This is even though some farmers in Nepal have adjusted well to apply recommendations provided by the plant doctors or extension officers (Adhikari et al., 2017).

The accessibility of plant healthcare can be influenced by the geographical area or distance to the plant health clinic (Adhikari et al. 2016). Sometimes, farmers would not know about the availability and accessibility of plant clinics due to lack of awareness and information (Madula et al., 2016; Musebe et al., 2018). Since the use of mobile phones is common among smallholder farmers, these devices can be used by farmers to interact or send sample to the extension officers (Musungwini, 2018; Cameron et al., 2016).

\subsection{Impact of plant health clinics on smallholder farmers}

According to Bentley et al. (2011) in the study conducted in Bolivia, the establishment of plant clinic has assisted the majority of smallholder farmers to increase their production through advisory services.Plant clinics play a critical role in providing smallholder farmers and farming community towards plant pests and diseases diagnosis and in providing education awareness on plant health problem (Barnes, 1994). 
Plant health clinics are beneficial for smallholder farmers and rural communities by means of enhancing crop productivity and food security. Van der Linde and Rong (2019) provided fundamental basis of establishing of plant clinic to benefit smallholder farmers in South Africa The study conducted by Bentley et al. (2011) revealed that plant clinics could have a huge impact in terms of farmers' income return especially for those receiving trainings. The other positive impact for plant clinics identified includes providing advisory on plant health problems and gaps, recommendations on the safe use of pesticides and pest management and control strategies (Boa et al., 2015). Adhikari (2015) listed some of the impact outcomes of plant clinics which include:

- Increased smallholder farmers' knowledge and awareness,

- Increased knowledge and skill on plant health problems on extension support staff.

- Increased extension services to the smallholder farmers,

- Enhance number of extensionist trained on plant health problem,

- Increased access to extension services by farmers

- Increased and active participation of smallholder famers,

- Collaboration of stakeholders at all levels,

- Cost effective and increased in yield production.

\subsection{Challenges of the plant health clinics}

Plant health clinics have several challenges which affect their functioning in terms of providing accurate advisory services to smallholder farmers. The studies conducted by Bentley et al. (2018) revealed that some recommendations provided to smallholder farmers requires expensive inputs to manage pests. Musebe et al. (2018) found distance to the extension office or plant health clinic as a challenge to the smallholder farmers to access and visit plant clinics. Boa and Bentley (2015) conducted a study in Côte de Ivoire and recommended mobile plant clinics to be encouraged to reach where smallholder farmers are located. Regarding plant clinic in Malawi, distance and awareness were also found to be fundamental limitations to smallholder farmers (Madula et al., 2016). Lack of extensive awareness on existing plant clinics and limited resources are found to be a common challenge in many plant clinics globally (Masebe et al., 2018). In Uganda, plant clinics were found to be experiencing challenges due to policy imperatives and institutional arrangement (Danielsen et al., 2014). Other plant health clinics do not have required resources and technology to operate. In some cases, plant clinic trainers have challenge to adjust with new technology (Wright et al., 2016).

Davis et al. (2018) outlines some limitations relating to many plant clinics across the globe which include:

- Arrangement and scheduling of information session and/ meeting with smallholder farmers,

- Poor attendance due to lack of awareness,

- Limited knowledge of smallholder farmers which lead to not accepting the advice from the plant operators, and

- Knowledge gaps of plant clinic operators. 
Based on the above, most smallholder farmers and extensionists experience constrain in terms of plant pest and disease management and control.

\subsection{Model for a sustainable, efficient and effective use of plant health clinics}

The model for Plant clinic can be defined as a mechanism in which the smallholder farmers obtained primary plant health advisory services relating to various plant health problems on their crops. The model differs from country to country, however, Centre for Agriculture and Bioscience (CABI) preferred model wherein there are collaborations between spheres of government: National, Provincial and Local government. In other countries, there are various systems in which funding is coordinated, for example, sponsorship, government as well as state own enterprises (Jenner, 2019). The model for plant clinics can be similar to those of animal healthcare (Bentley et al., 2009). Plant clinics differ: there are fixed and mobile clinics (Boa et al., 2015; Kelly, 2009). Appropriate model for plant health clinic to enhance services delivery in terms of coverage, access and the quality of plant healthcare is found to be a mobile system. In assessing various plant health clinics approaches, Jenner (2019) provided some of the key functional areas of plant health clinics as follows:

- Linkages among stakeholders under plant health system,

- Inclusive approach to all relevant stakeholders,

- Increase interaction between extension officers and farmers,

- Provide a diagnosis services and solution to a plant health problem,

- Provide early detection of pest and reporting to the relevant authority,

- Record keeping of plant pest problem and other information.

\section{CONCLUSIONS}

Mobile plant health clinics are valuable tools for farmers to understand more on plant pests and diseases diagnosis. Plant health clinics provide basic plant health services through advisory and recommendations provided to the smallholder farmers. Worldwide, there are various clinics established to assist smallholder farmers. It can be concluded that globally, plant clinics system and/or framework is similar although the resources vary as per country. Pant health clinics' knowledge, awareness accessibility and satisfaction of the smallholder farmers are very important for efficiency and effectiveness. This review found that plant clinics are critical for efficient and effective early diagnosis and detection of plant pests and diseases. It could be further deduced that the plant clinic framework worldwide is similar to those on animal and human health. However, the plant clinics concept is not yet widely adopted by many countries, especially in African countries. Considering the importance of plant clinics, countries should consider establishment of effective plant clinic model which is accessible at government level to assist farmers, especially smallholders' farmers.

Our next research prospect for plant health clinics would be to conduct a research in South Africa, Limpopo Province in the Vhembe District: (1) To examine smallholder farmers' knowledge, awareness, accessibility and satisfaction of plant health clinic in the study area (2) To analyse the determinants of smallholder farmers' knowledge, awareness, accessibility and 
satisfaction of plant health clinic in the study area (3) To identify and evaluate limitations of the existing plant health clinic militating against its utilization by smallholder farmers in the study area (4) To develop the appropriate and functional framework for a sustainable, efficient and effective use of plant health clinic in the study area.

\section{REFERENCES}

ADHIKARI, D., SHARMA, D.R., PANDIT, V., SCHAFFNER, U., JENNER, W. \& DOUGOUD, J., 2017. Coverage and access of plant clinic in Nepal. Journal of Agriculture and Environment, 18, 51-58.

ADHIKARI, R.K., REGMI, P.P., THAPA, R.B. \& BOA, E., 2015. SWOT analysis of Plant Health Clinics as perceived by plant doctors in Nepal. Journal of the Institute of Agriculture and Animal Science, 137-146.

ADHIKARI, R.K., REGMI, P.P., THAPA, R.B. \& BOA, E., 2015. SWOT analysis of Plant Health Clinics as perceived by plant doctors in Nepal. Journal of the Institute of Agriculture and Animal Science, 137-146.

ADHIKARI, R., REGMI, P.P., THAPA, R.B., DHOJ, Y.G.C. \& BOA, E., 2016. Determinants of farmers' participation in plant health clinics in Nepal. J. Agric. Sci, 14, 290-299.

AGRICULTURAL RESEARCH COUNCIL (ARC)., 2018A. Plant Health and Protection. Global Plant Clinics. Pretoria. www.arc.agric.za. Accessed 2018.

AGRICULTURAL RESEARCH COUNCIL (ARC)., 2018B. Plant Health and Protection. Products and Services. Pretoria.www.arc.agric.za.

ALOKIT, C., TUKAHIRWA, B., ORUKA, D., OKOTEL, M., BUKENYA, C. \& MULEMA, J., 2014. Reaching out to farmers with plant health clinics in Uganda. Uganda Journal of Agricultural Sciences, 15(1), 15-26.

AUSHER, R., BEN-ZE'EV, I.S. \& BLACK, R., 1996. The role of plant clinics in plant disease diagnosis and education in developing countries. Annual review of phytopathology, 34(1), 51-66.

AZIMI, R., ALLAHYARI, M.S., DAMALAS, C.A. \& KAVOOSI-KALASHAMI, M., 2017. Technical performance of Plant Clinics as providers of crop protection services: The case of Guilan Province, Iran. Crop Protection, 101, 12-18.

BANDARA P.T. \& KULATUNGA W.M., 2014. Using the crop clinic concept to minimize the indiscriminate use of pesticides and promoting effective judicious pesticide use.

BARNES, L. W., 1994. The role of plant clinics in disease diagnosis and education: A North American Perspective. Annu. Rev. Phytopathol.32: 601-9.

BENIN, S., NKONYA, E., OKECHO, G., PENDER, J., NAHDY, S. \& MUGARURA, S., 2007. Assessing the impact of the National Agricultural Advisory Services (NAADS) in the Uganda rural livelihoods. Intl Food Policy Res Inst.

BENTLEY, J.W., BOA, E., DANIELSEN, S., FRANCO, P., ANTEZANA, O., VILLARROEL, B. \& HERBAS, J., 2009. Plant health clinics in Bolivia 2000-2009: operations and preliminary results. Food Security, 1(3), 371-386. 
BENTLEY, J.W., DANIELSEN, S., PHIRI, N., TEGHA, Y.C., NYALUGWE, N., NEVES, E. \& SHARMA, D.R., 2018. Farmer responses to technical advice offered at plant clinics in Malawi, Costa Rica and Nepal. International journal of agricultural sustainability, 16(2), 187-200.

BENTLEY, J., BOA, E., ALMENDRAS, F., FRANCO, P., ANTEZANA, O., DÍAZ, O. \& VILLARROEL, J., 2011. How farmers benefit from plant clinics: an impact study in Bolivia. International Journal of Agricultural Sustainability, 9(3), 393-408.

BETT, E., MUGWE, J., NYALUGWE, N. HARAMAN, E., WILliAMS, F., TAMBO, J., WOOD, A. \& BUNDI, M., 2018. Impact of plant clinics on disease and pest management, tomato productivity and profitability in Malawi. CABI Working Paper 11, 30pp.

BOA, E., 2009. How the global plant clinic began. Outlooks on Pest Management, 20(3), 112116.

BOA, E. \& BENTLEY, J., 2015. Lethal yellowing of coconut palm in Côte d'Ivoire: getting started with plant health clinics and going public.

BOA, E. \& HARLING, R., 2007. Starting plant health clinics in Indonesia.

BOA, E. \& HARLING, R., 2008. Starting plant health clinics in Nepal.

BOA, E., DANIELSEN, S. \& HAESEN, S., 2015. Better Together: identifying the benefits of a closer integration between plant health, one health and agriculture. CABI.

BOA, E., FRANCO, J., CHAUDHURY, M., SIMBALAYA, P. \& VAN DER LINDE, E., 2016. Plant health clinics. What Works in Rural Advisory Services?, 81.

BUKENYA, C., 2010. Meeting Farmer Demand? An Assessment of Extension Reform in Uganda." PhD thesis, Wageningen University, Netherlands.

BRUBAKER, J., DANIELSEN, S., OLUPOT, M., ROMNEY, D. \& OCHATUM, N., 2013. Impact evaluation of plant clinics: Teso, Uganda. CABI Working Paper, (6).

CABI., 2015. Plantwise strategy 2015-2020. Wallingford, UK: CABI. Available at: http://www.plantwise.org/about-plantwise/strategy/

CAMERON, K.H., SOMACHANDRA, K.P., CURRY, C.N., JENNER, W.H. \& HOBBS, S.L., 2016. Delivering actionable plant health knowledge to smallholder farmers through the plantwise program. Journal of agricultural \& food information, 17(4), 212-229.

CHI, T.T.N. \& YAMADA, R., 2002. Factors affecting farmers' adoption of technologies in farming system: A case study in Omon district, Can The province, Mekong Delta. Omonrice, 10, 94-100.

DANIELSEN, S. \& KELLY, P., 2010. A novel approach to quality assessment of plant health clinics. International Journal of Agricultural Sustainability, 8(4), 257-269.

DANIELSEN, S. \& MATSIKO, F.B., 2016. Using a plant health system framework to assess plant clinic performance in Uganda. Food Security, 8(2), 345-359

DANIELSEN, S., BOA, E., MAFABI, M., MUTEBI, E., REEDER, R., KABEERE, F. \& KARYEIJA, R., 2013. Using plant clinic registers to assess the quality of diagnoses and 
advice given to farmers: a case study from Uganda. The Journal of Agricultural Education and Extension, 19(2), 183-201.

DANIELSEN, S., MATSIKO, F.B. \& KJEAR, A.M., 2014. Implementing plant clinics in the maelstrom of policy reform in Uganda. Food Security, 6(6), 807-818.

DAVIS, K., BOHN, A., FRANZEL, S., BLUM, M., RIECKMANN, U., RAJ, S., HUSSEIN, K. \& ERNEST, N., 2018. What Works in Rural Advisory Services? Global Good Practice Notes. Lausanne, Switzerland: GFRAS.

DEPARTMENT OF AGRICULTURE, FORESTRY AND FISHERIES (DAFF)., 2017. Pest alert: Detection of a new pest caterpillar for the first time in South Africa. Media release.

ETWIRE, P.M., DOGBE, W., WIREDU, A.N., MARTEY, E., ETWIRE, E., OWUSU, R.K. \& WAHAGA, E., 2013. Factors Influencing Farmer's Participation in Agricultural Projects: The case of the Agricultural Value Chain Mentorship Project in the Northern Region of Ghana. J. Econ.Sustain. Dev. 4: 36-43.

FLOOD, J., 2010. The importance of plant health to food security. Food Security, 2(3), 215231.

FOOD AND AGRICULTURE ORGANISATION., 2018. International Plant Protection Convention (IPPC). International Standards for Phytosanitary Measures (ISPM 6): Guidelines for surveillance.

FOOD AND AGRICULTURE ORGANISATION (FAO)., 2017. International Standards for Phytosanitary Measures (ISPM 17). Pest Reporting. International Plant Protection Convention (IPPC). Rome.

FOOD AND AGRICULTURE ORGANISATION., 2011. International Plant Protection Convention (IPPC). Rome.

JACKSON, L.D. \& FIESELMANN, D.A., 2011. The Cooperative Agricultural Pest Survey (CAPS) program. Scientific support to optimize a national program. United States Department of Agriculture: Animal and Plant Health Inspection Service (USDA: APHIS), Plant Protection and Quarantine (PPQ).

JENNER, W., 2019. Plant clinics as embedded services? CABI Switzerlan. Available from www.plantwise.org [Accessed 23 March 2019].

JONES, A.D. \& EJETA, G., 2016. A new global agenda for nutrition and health: the importance of agriculture and food systems. Bulletin of the World Health Organization, 94(3), 228.

KALARIS, T., FIESELMANN, D., MAGAREY, R., COLUNGA-GARCIA, M., RODA, A., HARDIE, D. \& WHITTLE, P., 2014. The role of surveillance methods and technologies in plant biosecurity. In The handbook of plant biosecurity (pp. 309-337). Springer, Dordrecht.

KANSIIME, M.K., MUGAMBI, I., MIGIRO, L., OTIENO, W. \& OCHIENG, J., 2020. Farmer participation and motivation for repeat plant clinic use: Implications for delivery of plant health advice in Kenya. Cogent Environmental Science, 6(1), 1750539. 
KARUBANGA, G., MATSIKO, F.B. \& DANIELSEN, S., 2017. Access and coverage: which farmers do plant clinics reach in Uganda?. Development in Practice, 27(8), 1091-1102.

KELLY, P., 2009. Getting Better All the Time. CABI-Global Plant Clinic, London [available at $w w w$. Research for development. info/PDF/Outputs/Misc_Crop/REPBD10_GettingBetteralltheTime.pdf], accessed, 30.

LUQMAN, M., ASHRAF, S., YASEEN, M. \& SARWAR, M.K., 2020. Plant Health Clinics (PHC) in Pakistan: Operations and Prospects. In: Ul Haq I., Ijaz S. (eds) Plant Disease Management Strategies for Sustainable Agriculture through Traditional and Modern Approaches. Sustainability in Plant and Crop Protection, vol 13. Springer, Cham. https://doi.org/10.1007/978-3-030-35955-3_12.

MADULA, B., MANYANI, T., CHIKOMOLA, A. \& KAYUNI, S., 2016. Farmers participation in plant clinics in Malawi. Promoting farmer participation in innovative agricultural advisory services. Department of Agricultural Extension Services, Ministry of Agriculture, Self Help Africa, Malawi.

MAJUGA, J.C.N., UZAYISENGA, B., KALISA, J.P., ALMEKINDERS, C. \& DANIELSEN, S., 2018. "Here we give advice for free": the functioning of plant clinics in Rwanda. Development in Practice, 28(7), 858-871.

MARTEY, E., ETWIRE, P.M., WIREDU, A.N. \& DOGBE, W., 2014. Factors influencing willingness to participate in multi-stakeholder platform by smallholder farmers in Northern Ghana: implication for research and development. Agric. Food Econ. 2. doi:10.1186/s40100-014-0011-4.

MUSEBE, R.O., MUGAMBI, I., WILliAMS, F., MULAA, M., NAMBIRO, E. \& CHEGE, F., 2018. Gender differences in the use of plant health information services: A case of plant clinics under Plantwise Program in Kenya. African Journal of Agricultural Research.CAB International. Nairobi, Kenya.

MUSUNGWINI, S., 2018. Mobile phone use by Zimbabwean smallholder farmers: a baseline study. African Journal of Information and Communication, 22, 29-52.

NEGUSSIE, E., KARANJA, P., ROMNEY, D., MURIITHI, C., KAMAU, R., BOA, E., ZOMBE, N., WANJIKU, R., MURAGE, N., MULAA, M., DAY, R. \& MUTISYA, J., 2011. 'Role of plant health clinics in enhancing adaptive capacity to climate induced plant health problems: Experiences from Kenya'. Paper presented at the Africa Adapt Climate Change Symposium, Addis Ababa, Ethiopia, 9-11 March.

OCHILO, W.N., OTIPA, M., ORONJE, M., CHEGE, F., LINGEERA, E.K., LUSENAKA,E. \& OKONJO, E.O., 2018. Pest management practices prescribed by frontline extension workers in the smallholder agricultural subsector of Kenya. Journal of Integrated Pest Management, 9(1), 15.

OERKE, E.C., 2006. Crop losses to pests. The Journal of Agricultural Science, 144(1), 31-43.

PLANTWISE, 2014. Plant Clinic data management. IPPC National Reporting Obligations and Plantwise. Nairobi, Kenya. www.plantwise.org. 
RAMBAULI, M., ANTWI, A.M. \& MUDAU, F.N., 2019. National and provincial officials' knowledge on phytosanitary matters for food security in South Africa. South African Journal of Agricultural Extension, 47(1), 151-163.

REPUBLIC OF SOUTH AFRICA (RSA)., 2014. Plant Health (Phytosanitary) Policy of South Africa. Department of Agriculture, Forestry and Fisheries (DAFF). Pretoria: Government Gazette No.38102.

REPUBLIC OF SOUTH AFRICA (RSA)., 2017. Agricultural Pests Act No.36 of 1983 (Act No.36 of 1983) as amended. Control Measures Amendment. R.1271 of 17 January 2017. Republic of South Africa. Pretoria.

SIMELA, L., 2012. Options for the delivery of primary animal health care for livestock farmers on communal land in South Africa: Mnisi Community case study (Doctoral dissertation, University of Pretoria).

SRIVASTAVA, M.P., 2013. Plant clinic towards plant health and food security. International Journal of Phytopathology, 2(3), 193-203.

SRIVASTAVA, M.P., 2018. Observation on Plant Health Clinic: Diversification for strengthening Food Security. Curr. Inves Agri.Curr Res 2(5).

TAMBO, J.A., UZAYISENGA, B., MUGAMBI, I. \& BUNDI, M., 2020. Do Plant Clinics Improve Household Food Security? Evidence from Rwanda. Journal of Agricultural Economics.

VAKILIAN, K.A., 2017. Using networks in plant disease diagnosis. CAB Reviews, 12(047), $1-12$.

VAN DER LINDE, E. \& RONG, I., 2019. Mobile plant health clinics - a new approach to monitoring plant diseases in South Africa. Agricultural Research Council (ARC). Pretoria.

WRIGHT, H.J., OCHILO, W., PEARSON, A., FINEGOLD, C., ORONJE, M., WANJOHI, J., \& RUMSEY, A., 2016. Using ICT to strengthen agricultural extension systems for plant health. Journal of agricultural \& food information, 17(1), 23-36. 